Article

\title{
Impacts of Tourists' Sociodemographic Characteristics on the Travel Motivation and Satisfaction: The Case of Protected Areas in South China
}

\author{
Anson T. H. Ma ${ }^{1}$, Alice S. Y. Chow ${ }^{1}$, Lewis T. O. Cheung ${ }^{1, * \mathbb{C}}$, Karen M. Y. Lee ${ }^{1}{ }^{\mathbb{D}}$ and \\ Shuwen Liu $^{2}$ \\ 1 Department of Social Sciences, The Education University of Hong Kong, Hong Kong, China; \\ athma@eduhk.hk (A.T.H.M.); asychow@eduhk.hk (A.S.Y.C.); myklee@eduhk.hk (K.M.Y.L.) \\ 2 School of Arts and Social Sciences, The Open University of Hong Kong, Hong Kong, China; \\ swliu@ouhk.edu.hk \\ * Correspondence: ltocheung@eduhk.hk; Tel.: +852-2948-8908
}

Received: 17 August 2018; Accepted: 20 September 2018; Published: 22 September 2018

\begin{abstract}
Western studies on nature-based tourism have long explored the relationships among tourists' sociodemographic characteristics, motivation and satisfaction as a way of predicting their visitation patterns and travel behaviours. Relatively few studies have been conducted in the Chinese context given its varied and extensive landscapes. This paper seeks to fill this gap using data from questionnaire surveys conducted in two popular and prestigious forest nature reserves in Guangdong province between August and December 2015. Data collected were analyzed by multiple regression tests with socio-demographic factors as the predictors of travel motivation and satisfaction in SPSS 24.0. The key findings and observations include the following: First, contrary to some overseas studies, education level was negatively correlated with tourists' satisfaction with management and educational value. Second, age was positively correlated with the sense of relaxation and nature exploration. Third, education level had a negative correlation with motivation regarding social influence. Fourth, the influence of local culture helps differentiate Chinese tourists from Western tourists, implying that different management strategies should be adopted. All these findings offer insights to nature-based tourism operators that cater to the growing ranks of Chinese ecotourists.
\end{abstract}

Keywords: travel motivation; nature-based tourism; satisfaction; national forest parks; South China

\section{Introduction}

The tourism industry in China has been growing rapidly. In 2016, the number of Chinese outbound tourists reached 117 million, and Chinese tourists spent over 100 billion USD [1]. It is predicted that China will rank 3rd in the world in terms of long-term tourism growth [2]. Aside from the dominating market of mass tourism, the popularity of alternative tourism such as nature-based tourism has increased in the last decade [1], especially nature-based tourism in national parks [3]. The China Tourism Academy [1] reported that 30\% of outbound tourists in China have switched from traditional mass tourism destinations to more nature-based destinations such as Sri Lanka, Sabah, and Bali. China's intensive urban development [4,5] and growth in urban populations [6], health-threatening pollution [7] and degrading environment [8] are common reasons why tourists visit nature-based areas instead of cities [1,9]. Nature reserves in China have also been extensively developing local nature-based tourism to accommodate the vast number of domestic tourists [10]; e.g., forest parks in China accommodated over 0.8 billion tourists in 2015 and made over 87 billion of tourism revenue [11]. All these statistics showed the great number and contribution of Chinese tourists to the global tourism market. They also confirmed the importance of studying the characteristics of 
Chinese tourists in nature-based tourism so as to understand their motivation and potential impacts, which would help formulate management policies accordingly.

Apart from changes occurring in the industry, there was a noted evolution in the characteristics of tourists. At the beginning stage of tourism development, Chinese tourists were dominantly middle-upper class, middle-aged people; whilst in recent years, an increasing number of younger, more-educated middle-class people have been travelling [12].

Active and proper management is needed in nature-based areas such as nature reserves and national parks to cater to the increasing number of tourists without excessively damaging the environment [13]. Understanding the implications of tourists' sociodemographic and visitation characteristics, motivation and satisfaction is crucial for the facilitation of management plans $[14,15]$. It has been suggested that sociodemographic characteristics are indicators of tourist motivation $[16,17]$ and thus reflect the activities that tourists like to join, the places they like to visit and the potential impacts of these activities and places on the tourists. Likewise, both the sociodemographic characteristics and motivation of tourists could predict their level of satisfaction and future travel behaviour $[14,18,19]$.

Nature-based tourists' demographic characteristics, motivation and satisfaction have been studied fairly widely in the Western context, but research in China has been sparse given the country's large population and extensive natural landscape. Some studies have demonstrated that there are certain differences between Chinese and Western tourists and among tourists across nationalities [20,21]. Owing to drastically different sociodemographic backgrounds, findings in Western contexts might not help shed light on tourist behaviours in China. Sofield and Li [22] argued that while management of tourists could follow traditional Western guidelines, they should be ready to adapt according to the characteristics, background and culture of Chinese tourists. As motivation and satisfaction vary across nationalities as well as personalities, it pays to conduct a specific study in the Chinese context rather than relying on mainstream studies on Western nature-based tourists [16]. This study aims to (1) investigate and fill the research gap regarding the relationships among the sociodemographic characteristics, motivation and satisfaction of Chinese nature-based tourists; (2) understand the differences between Chinese and western tourists; and (3) provide information for improving the understanding and management of the growing number of nature-based tourists from China.

This paper will first discuss previous research on motivation, satisfaction and socio-demographic factors of global and Chinese tourists, the respective factors identified and correlations found. It will then introduce and explain the methods of this study, followed by the presentation of results from multiple regression tests. The discussion part of the study will compare results of Western studies with those of this study, indicate the significant characteristic of Chinese tourists, and highlight the key differences between Chinese and Western tourists. It will end with a discussion of the implications of the results on the management of tourists and protected areas.

\section{Literature Review}

Tourist motivation has been widely studied in the fields of nature-based tourism and ecotourism by various researchers [14,16,23-28]. Studies in this area can provide crucial information for the management of tourists, marketing strategy and product development in nature-based or protected areas [24,29]. Motivation refers to the psychological need and the feeling to fulfil desires [30], and it explains why tourists behave in a certain manner [29]. Motivation has been studied using different approaches, and the push-pull model of Crompton [31] has often been used. "Push" refers to the internal trigger for tourists to decide to travel and seek unspecified travel destinations, while "pull" refers to the external attraction of a certain destination that appeals to a tourist. Different researchers have aligned the push-pull forces with various constructs and factors of motivation. Fung and Jim [27] in their study of nature-based tourism in Hong Kong Geopark, identified three factors of motivation, including "nature ambience motivation", "inherent heritage motivations", and "social and accessibility motivations", with "nature ambience" being the most influential factor. Mehmetoglu 
and Normann [29] studied nature-based tourists in Norway and proposed the motivation factors of "physical activity", "relaxation", "escape", "novelty" and "prestige". In research on tourist motivations in Addo Elephant National Park [32], the six factors of "nature", "activities", "family socialization", "escape", "attraction", and "photography" were identified, with "escape" obtaining the highest mean score. Holden and Sparrowhawk [33] categorized the motivations of trekkers in Nepal into "relaxation", "thrills", "relationships", "self-esteem and development", and "fulfilment". Respondents of their study rated "relaxation" as the most important motivation for them to travel. In their study on Chinese forest park tourists, Luo and Deng [34] reported that "return to nature" was more important than "novelty/self-development" and "knowledge and fitness". Social, relaxation, escape, nature and recreation factors have commonly appeared in different studies. However, across these studies, the most important factor always varies with the sociodemographic backgrounds of the tourists and individual contexts.

The sociodemographic and visitation characteristics of tourists, such as age, education level, and income, could be good predictors of their motivation, as the association between these factors and motivation has been reported in previous studies. In terms of age, a few studies have found that older people or the elderly are usually more motivated by "novelty" [20,35]. However, the study conducted by Luo and Deng [34] on Chinese tourists showed that a negative relationship exists between age and the motivation of novelty seeking, indicating that younger tourists tend to seek novelty more. Kim et al. [17] also suggested that younger people are more motivated by novelty seeking than older people. For young people, it was reported that "recreation/physical activities", "enjoying nature", "prestige and impression" and "social seeking" were more important motivational factors [17,20,36,37]. Concerning the education level of tourists, more-educated tourists were suggested to be motivated more by "relax and escape", "knowledge seeking" and "socialization", while less-educated people were more associated with the factors of "prestige/impression" and "novelty" [17,37]. In terms of income, tourists in higher income groups rated the "appreciation of nature" and "escape and relaxation" as more important, while those in lower income groups showed a stronger preference for "knowledge seeking" [17,37].

Regarding the visitation pattern of tourists, Jang and Feng [35] in their study of Canadian tourists reported that the motivation of novelty positively influenced the mid-term repeated visit intention. Similarly, in a study on ecotourist motivation and revisit intention in South Korea, Lee, et al. [38] showed that the motivations of "relax and escape" and "knowledge seeking" were significant predictors of repeated visits. A study in Switzerland by Bieger and Laesser [39] indicated that tourists with social motivations tended to travel in larger groups.

In addition to sociodemographic and visitation characteristics, satisfaction is associated with the motivation of tourists, which has certain implications for nature-based tourism management. Tourist satisfaction refers to the positive feeling or pleasure gained after experiencing or consuming any tourism product [40] and includes the evaluation of the experience of travel or the tourism product against the tourists' motivation [41]. Various models of tourist satisfaction have been developed, and the expectancy-disconfirmation theory [42] is one of the most widely accepted models [18]. This model measures tourist satisfaction by allowing tourists to compare their expectations and perceptions of performance/actual experience. Previous studies have identified various factors of tourist satisfaction. Meng, et al. [43], in their study of nature-based tourism resort satisfaction in Southwest Virginia, identified factors of satisfaction, including "friendly service/quality", "outdoor activities", "lodging" and "natural scenery". The study by Tsiotsou and Vasioti [19] on tourism services in Greece identified a number of satisfaction factors including "personnel satisfaction", "food satisfaction", "excursion satisfaction", "socialization satisfaction" and "landscape satisfaction". In studying tourist satisfaction with forest recreation, Lee [44] used the following satisfaction factors: "information services", "recreation facilities" and "safety and sustainability". Adam, Adongo and Amuquandoh [16] studied the satisfaction and motivation of ecotourists at Kakum National Park using 
the following factors: "educational satisfaction", "social satisfaction", "sanitation satisfaction" and "relaxation satisfaction".

Measures of satisfaction with nature, social, service and facilities factors commonly appeared in different studies, a sign of their importance in reflecting and assessing the satisfaction level of tourists. Different studies have suggested that motivation shapes the expectations, behaviours and attitudes of tourists. Motivation influences the tourists' experience and helps them evaluate their experience compared to their expectations on the trip (e.g., on the environment, facilities or services), resulting in different levels of satisfaction $[45,46]$. Lee [14] observed that satisfaction was positively associated with current or future environmentally responsible behaviour and acted as a mediator to translate motivation into behaviour. Therefore, it is important for management to understand tourists' motivation and expectations in order to facilitate their positive experiences and increase tourist satisfaction, which can in turn encourage positive behaviour [47]. A few studies have suggested that a positive correlation exists between motivation and satisfaction [14,43,47]. Studies rarely investigated the influence of specific motivational factors on satisfaction, and this research gap has yet to be filled. Certain correlations allegedly exist between sociodemographic and visitation variables and satisfaction. The study by Ozdemir al et. [18] on tourist profiles and satisfaction in Turkey showed that the characteristics of being female, old, and highly educated with a low income level were correlated with a higher level of satisfaction. The study by Tsiotsou and Vasioti [19] on demographics and satisfaction with tourism services in Greece also supported the finding that older people with higher education levels tend to be more satisfied with their travel experiences. In their study on Madeira tourists, Barros and Machado [48] reported that older, male and more-educated tourists would likely have longer stays.

\section{Methodology}

\subsection{Study Area}

The Nanling National Forest Park and the Dinghushan National Nature Reserve, which are situated in Guangdong province (Figure 1), were selected to be the study areas for the questionnaire surveys. Guangdong province has the most protected areas and ranks among the top for tourist visitation rates, revenue and land coverage in China [49], indicating that visitors of protected areas in this province may represent Chinese tourists, particularly those from Southern China. Both Nanling and Dinghushan are regarded as having the highest level of protection afforded by the protected area system of China due to their national-level status. A national-level status indicates that the environmental, tourism and sociocultural values associated with the particular protected area are among the most important and are highly representative of other areas in China.

Dinghushan was established as a nature reserve when protected area policies were being developed in the 1950s. The designation of Nanling National Forest Park also occurred fairly early in 1993, when Guangdong province started establishing forest parks for tourism and conservation.

The visitation rates of both areas have been fairly high; approximately $0.6-0.8$ million tourists visit Dinghushan annually [50], and Nanling attracted hundreds of thousands of visitors in 2017. These data highlight the popularity of these two areas as nature-based hotspots compared to other protected areas in Southern China. Dinghushan and Nanling would, therefore, be suitable and highly representative study areas for this study on Chinese forest nature-based tourists due to their national status, exceptionally long history of establishment and popularity for nature-based tourism. 


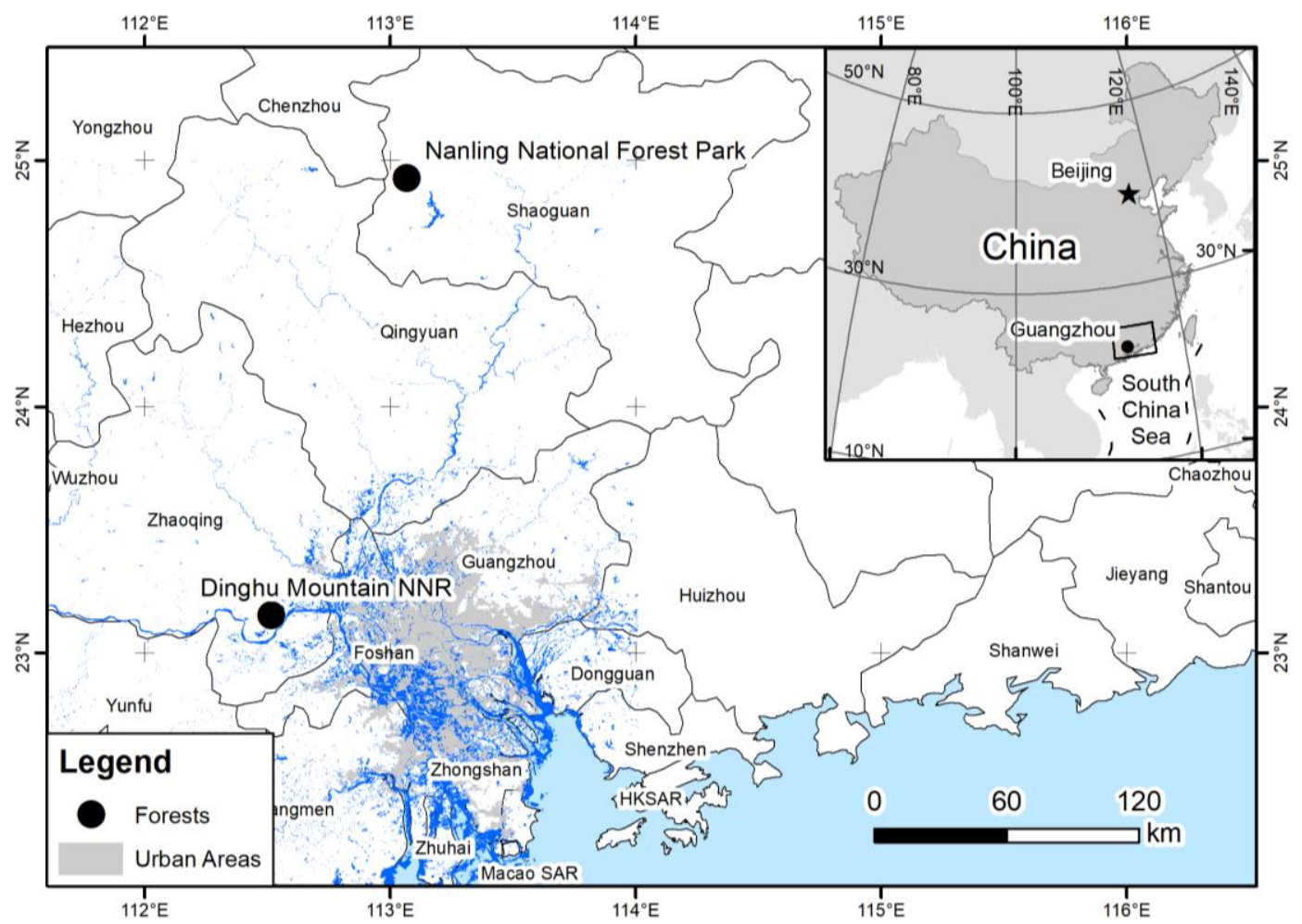

Figure 1. Location of Nanling National Forest Park and Dinghushan National Nature Reserve.

\subsection{Questionnaire Design}

The questionnaire for this study was divided into three parts and included items on motivation, satisfaction and sociodemographic information. For the first two parts, a five-point Likert type scale was utilized, and the scale ranged from "strongly disagree" (1) to "strongly agree" (5).

The first part of the questionnaire included 16 items that captured the motivations of the respondents. The design of the motivational items was adapted from the Canadian Tourism Attitude and Motivation Study [51], with references to multiple studies on the motivation of nature-based tourists $[14,24,27,34,47]$. Previous studies have identified various aspects and factors of tourist motivation, including social interaction, contact with nature, recreation and physical activities, prestige and impression, and escape and relaxation [20,27,29,32-34,37]. Different types of motivations were included in the design of the motivational items to ensure that the motivation level of the tourists was comprehensively measured. Further factor analysis was conducted to restructure items into motivational factors.

The second part of the questionnaire consists of eight items that assess the satisfaction level of the respondents. Multiple categories of satisfaction items were employed, with references to various studies on tourist satisfaction $[14,16,18,19]$. These items were modified according to the local context, e.g., D5 and D6 were added to understand the satisfaction of Chinese on facilities regarding tourism resource and security which is not often asked. Three main categories of satisfaction were included in this questionnaire. The first category consists of items D1 and D2, which assess the satisfaction of respondents with natural resources such as the landscape and organisms in the forest parks. The second category addressed items regarding facilities and transportation and included items D3, D5 and D6, which assess respondents' level of satisfaction with their experiences with the recreation and safety facilities and transport system of the park. The third category addressed items regarding management and education and included items D7 and D8, which measure respondents' level of satisfaction with the tourism and conservation management policies and education resources. 
The last part of the questionnaire measured the sociodemographic and visitation characteristics of the respondents. Sociodemographic and visitation information, including age, education level, income, occupation, gender, and visitation patterns, was collected.

\subsection{Sampling Method \& Data Analysis}

An on-site survey was conducted from August to December of 2015. The survey was carried out on both weekdays and weekends at the Nanling National Forest Park and the Dinghushan National Nature Reserve; this method helped to capture all types of nature-based tourists and their various visitation patterns. A training and briefing session was provided to five undergraduate students before the survey to equip them with questionnaire survey skills and inform them of the background of the study. A pilot study was carried out before the actual survey. The questionnaire was conducted in a face-to-face manner by the undergraduate students, and a researcher supervised the process. Undergraduate student helpers would assist respondents to complete the questionnaire and help to explain any misunderstanding or confusion of the participants. Random sampling was adopted. For every five visitors, one was randomly invited to an interview in a designated location; only Chinese interviewees aged 18 or older were invited to participate in the study. The duration of the questionnaire was approximately $15 \mathrm{~min}$. In gratitude for their voluntary participation in the survey, every interviewee who completed the questionnaire received a souvenir. At the Nanling National Forest Park, 294 targets were invited to participate in interviews; 94 rejected the invitation, resulting in a response rate of $68 \%$. At the Dinghushan National Nature Reserve, 360 targets were invited to participate in interviews; 158 refused to participate, resulting in a response rate of $56.1 \%$. The slight difference in response rate may be influenced by the weather of the survey period. The survey in Nanling was carried out earlier in August with warmer weather, while that of Dinghushan was done later so the weather is poorly and visitors were less willing to stay for the questionnaire. In addition, as the survey took a relatively long time to complete, this may also discourage people to participate. In total, 654 targets were approached, and 402 completed the questionnaire, resulting in a total response rate of $61.5 \%$. This response rate compared to other studies in Chinese protected area, e.g., Fung and Jim [27] who had a response rate of only $56.9 \%$, was still fair.

Common method bias was controlled in this study by a few procedural remedies suggested by Podsakoff, et al. [52]. To eliminate common scale properties, wordings in the scale of the motivation and satisfaction were slightly altered although the scale points were kept. In the motivation items, respondents were asked to answer if they are agreeing with the statement, while in satisfaction part, respondents were asked to show their satisfaction level of an item instead of how much they agree with the statement. This method would prevent the cognition effect that causes respondents to answer consecutive questions similarly due to the similarity in question format [52]. Another approach suggested by Podsakoff al et. [52] was to eliminate ambiguity by improving items. Potential ambiguity concerns were addressed during the survey process; helpers were responsible for explaining items, wordings or meanings to respondents if they were confused.

SPSS 24.0 was used to analyse the collected data. Exploratory factor analysis (EFA) was carried out to identify different factors of travel motivation. Structural equation model has been performed, but the model fitness was not acceptable for adopting this statistical method. Therefore, regression analysis was chosen to analyse the associations among the tourists' sociodemographic and visitation characteristics, motivation and satisfaction level.

To test internal consistency of the motivational and satisfaction items, Cronbach's Alpha developed by Cronbach [53] was employed. Obtaining a high level of internal consistency, shown as the alpha value, would ensure the validity and reliability of the study and the correlation between the studied items [54]. Alpha of each factor identified from EFA would be tested individually to avoid the problem of multidimensionality which would lead to errors in the estimation of reliability [54]. Previous studies have suggested that the acceptable range of alpha value would be $0.70-0.95[55,56]$. Nunnally al et. [57] suggested that in newly developed measures, alpha value of $>0.6$ would be 
acceptable. In EFA, according to a widely accepted rule suggested by Kaiser [58], factors from EFA should attain an eigenvalue of 1 or above. As commonly recognized, loadings of items in factor should all be above 0.4 [59].

Common method bias would be tested in this study by examining the Harman's single factor score as suggested in previous studies [52,60]. It was suggested that a total variance below $50 \%$ would indicate that the data and result were not affected by common method bias $[52,60]$.

\section{Results}

\subsection{Sociodemographic \& Visitation Characteristics}

According to Table 1, 187 of the respondents were male, and 215 were female, representing $46.5 \%$ and $54.5 \%$ of the total respondents, respectively. The majority of the respondents (57.9\%) were below 35 years old, with only a very few aged 55 or above (3.9\%). The youngest tourists, aged 18-24 years old, were the largest group (30.3\%). Most of the respondents $(72.1 \%)$ were employed, followed by the second largest group, who were students $(19.7 \%)$. Unemployed and retired people represented only $8.2 \%$ of the total respondents. The majority of the respondents had attained an undergraduate degree or higher $(65.6 \%)$. Fewer had only a senior secondary level of education $(22.9 \%)$, and only $11.4 \%$ had a junior secondary level or less. A large proportion of the respondents (56.7\%) earned $4000 \mathrm{RMB}$ or less per month. Only $17 \%$ of the respondents had a monthly income of more than 7000 RMB.

Table 1. Respondents socio-demographic and visitation characteristics.

\begin{tabular}{|c|c|c|c|c|c|}
\hline & Number & $\%$ & & Number & $\%$ \\
\hline Gender & & & \multicolumn{3}{|c|}{ Visitation rate of national park in China (times per year) } \\
\hline Male & 187 & 46.5 & 1 & 76 & 18.9 \\
\hline \multirow[t]{2}{*}{ Female } & 215 & 54.5 & $2-5$ & 256 & 63.7 \\
\hline & & & $6-9$ & 36 & 9.0 \\
\hline Age & & & 10 or above & 34 & 8.5 \\
\hline $18-24$ & 122 & 30.3 & & & \\
\hline $25-34$ & 111 & 27.6 & \multicolumn{3}{|c|}{ Number of visit to Nanling forest park/Dinghushan nature reserve } \\
\hline $35-44$ & 95 & 23.6 & 1 & $255^{\circ}$ & 63.4 \\
\hline $45-54$ & 58 & 14.4 & 2 & 59 & 14.7 \\
\hline $55-65$ & 15 & 3.7 & 3 & 34 & 8.5 \\
\hline$>65$ & 1 & 0.2 & 4 or above & 54 & 13.4 \\
\hline Occupation & \multicolumn{5}{|c|}{ Group size (no. of person) } \\
\hline Student & 79 & 19.7 & 1 & 8 & 2.00 \\
\hline Unemployed & 17 & 4.2 & $2-5$ & 183 & 45.5 \\
\hline Employed & 290 & 72.1 & $6-9$ & 91 & 22.6 \\
\hline Retired & 16 & 4.0 & 10 or above & 120 & 29.9 \\
\hline Education & \multicolumn{5}{|c|}{ Duration of visit (days) } \\
\hline Primary school or below & 5 & 1.2 & $0-1$ & 258 & 64.2 \\
\hline Junior Secondary School & 41 & 10.2 & 2 & 102 & 25.4 \\
\hline Senior Secondary School & 92 & 22.9 & $3-5$ & 25 & 6.2 \\
\hline Undergraduate & 249 & 61.9 & 6 or above & 17 & 4.2 \\
\hline Postgraduate & 15 & 3.7 & & & \\
\hline \multicolumn{3}{|l|}{ Monthly Income $(R M B)$ * } & \multicolumn{3}{|l|}{ Place of residence } \\
\hline$<1000$ & 92 & 23.1 & Guangdong & 387 & 96.5 \\
\hline $1001-2500$ & 51 & 12.8 & Shanghai & 3 & 0.5 \\
\hline $2501-4000$ & 83 & 20.8 & Jiangsu & 1 & 0.2 \\
\hline $4001-5500$ & 61 & 15.3 & Hunan & 6 & 1.4 \\
\hline $5501-7000$ & 44 & 11.0 & Fujian & 1 & 0.2 \\
\hline \multirow[t]{2}{*}{$>7000$} & 68 & 17.0 & Hong Kong & 4 & 1.0 \\
\hline & & & Total & 402 & 100 \\
\hline
\end{tabular}

* Conversation rate of RMB: USD is approximately 6.3:1. 
Regarding the visitation pattern of the respondents, the majority of the tourists (63.7\%) visited national parks $2-5$ times a year. A small proportion (8.5\%) visited 10 times or more. Many of the respondents (63.4\%) were first-time visitors of the Nanling National Forest Park or the Dinghushan National Nature Reserve. A large proportion of the respondents travelled in groups of 2-5 people, followed by those who travelled in groups of 10 or more $(29.9 \%)$. Very few $(2 \%)$ of the respondents travelled alone. The respondents preferred day trips, as most of them travelled to the forest park or nature reserve for only a day or less. Some of the respondents (25.4\%) stayed for 2 days.

\subsection{Common Method Bias and Reliaiblity and Validitiy Test for EFA}

Total percentage of variance resulted from the Harman's single factor score test was 21.5\%, which is much lower than the limit of $50 \%$, thus showing that common method bias was not a concern for the data and results of this study. To confirm the convergent validity, the factor loadings of items were examined. All the factor loadings of the 2 EFA of motivational and satisfaction factors were $>0,4$, which is above the minimal limit of 0.4 [61], therefore the convergent validity is confirmed. The factor correlation matrix was examined for discriminant validity. All correlations between factors were below 0.7 , showing that factors were distinct and uncorrelated and confirmed the discriminant validity of the 2 EFA [61]. Reliability was assessed by Cronbach alpha as mentioned above in the method part; the alpha value of three motivational factors and two satisfaction factors were $>0.7$, and the motivational factor on social influence and physical refreshment was $>0.6$, which confirmed the reliability of all the factors extracted.

\subsection{Motivation of Respondents}

According to Table 2, the mean score of the motivations ranged from 3.45 to 4.54. "A13. I would like to get close to nature" (4.54), "A8. I would like to see as much as possible in the time available" (4.43) and "A14. I would like to refresh my mental state" (4.41) were rated as the most important motivations. The lowest scored item was "A10. My friends and family tell me to visit the park" (3.56) and "A5. I would like to find thrills and excitement in this park" (3.57).

To investigate the underlying dimensions of the motivational items, factor analysis was carried out (Table 2). EFA was conducted with varimax rotation. A four-factor solution resulted from the 16 motivational items. The eigenvalues of all three factors were higher than 1.0 and explained $51.52 \%$ of the total variance.

The first factor "relaxation and nature exploration" explained $22.25 \%$ of the variance and obtained an eigenvalue of 3.338 and a Cronbach's alpha of 0.802 . Cronbach's alpha value of $>0.7$ would be acceptable and reliable for further analysis as mentioned above. This factor consists of seven items, including A7, A8, A9, A13, A14, A15 and A22. These factors commonly capture the motivation of respondents to explore or enjoy nature and to mentally relax and release their pressure. This motivational factor is similar to the factors of "relax", "escape" and "nature" in a number of studies [16, $17,27]$. The mean score of this factor is the highest among all the factors, showing that it motivates tourists the most, as most of the highly rated items were within this factor. This finding is consistent with many previous studies suggesting that relaxation, escape and nature-connectedness are most important to tourists $[27,33,34]$. The second factor "novelty seeking" included items A2, A3, A4, A5 and A6; it explained $16.34 \%$ of the variance and obtained an eigenvalue of 2.49 and a Cronbach's alpha of 0.774 . These items reflect the motivation of respondents regarding their tendency to search for novelty in terms of knowledge, activities, excitement or people. Previous studies [24,29,33,34] have suggested similar factors, such as "travel for novelty", "knowledge motivation", and "novelty-self-development". The last factor was named "social influence and physical refreshment" and yielded a variance of 12.92. This factor obtained an eigenvalue of 1.939 and a Cronbach's alpha of 0.660 . As the eigenvalue of this factor was above one and the loadings of items were above 0.4 , it would be a suitable factor for EFA even through the Alpha value is slightly lower than 0.7. Items A10, A11 and A12 were included in this factor. This factor was used to indicate the motivation of respondents to travel under the 
influence of their family and friends, either in the form of encouragement or prestige gained. Many studies on tourist motivation $[16,17,27,29,32]$ have identified similar factors, e.g., "social interaction", "socialization", and "prestige and impression". This factor has the lowest mean score and is the least important of the four factors. A few studies have also reported similar findings indicating that social motivations were relatively less important $[27,32]$.

Table 2. Exploratory Factor Analysis (EFA) of tourist motivations.

\begin{tabular}{|c|c|c|c|c|c|c|}
\hline \multirow[b]{2}{*}{ Factors and Items } & \multirow[b]{2}{*}{ Mean } & \multirow[b]{2}{*}{$\begin{array}{l}\text { Standard } \\
\text { Deviation }\end{array}$} & \multirow[b]{2}{*}{$\begin{array}{l}\text { Cronbach's } \\
\text { Alpha }\end{array}$} & \multicolumn{3}{|c|}{$\begin{array}{c}\text { Rotated (Varimax) } \\
\text { Components Factor Loading }\end{array}$} \\
\hline & & & & 1 & 2 & 3 \\
\hline $\begin{array}{l}\text { Factor 1. Relaxation and nature } \\
\text { exploration (M1) }\end{array}$ & 4.359 & & 0.802 & & & \\
\hline A7. I would like to have fun in this park. & 4.35 & 0.804 & & 0.482 & & \\
\hline $\begin{array}{l}\text { A8. I would like to see as much as } \\
\text { possible in the time available. }\end{array}$ & 4.43 & 0.886 & & 0.572 & & \\
\hline $\begin{array}{l}\text { A9. I would like to release the pressure } \\
\text { from my work or daily life. }\end{array}$ & 4.36 & 0.837 & & 0.558 & & \\
\hline A13. I would like to get close to nature. & 4.54 & 0.734 & & 0.796 & & \\
\hline $\begin{array}{l}\text { A14. I would like to refresh my } \\
\text { mental state. }\end{array}$ & 4.41 & 0.832 & & 0.681 & & \\
\hline $\begin{array}{l}\text { A15. I would like to participate in } \\
\text { recreational activities (e.g., photography, } \\
\text { hiking) at the park. }\end{array}$ & 4.09 & 1.005 & & 0.584 & & \\
\hline $\begin{array}{l}\text { A22. I love the natural scenery of } \\
\text { this park. }\end{array}$ & 4.33 & 0.717 & & 0.611 & & \\
\hline Factor 2. Novelty seeking (M2) & 3.976 & & 0.774 & & & \\
\hline $\begin{array}{l}\text { A2. I would like to learn new things } \\
\text { (e.g., geographical and } \\
\text { biological knowledge). }\end{array}$ & 4.00 & 1.015 & & & 0.509 & \\
\hline $\begin{array}{l}\text { A3. I must be occupied with activities in } \\
\text { my spare time. }\end{array}$ & 4.27 & 0.838 & & & 0.456 & \\
\hline $\begin{array}{l}\text { A4. I would like to be free to act the way } \\
\text { I feel in this park. }\end{array}$ & 4.17 & 0.950 & & & 0.468 & \\
\hline $\begin{array}{l}\text { A5. I would like to find thrills and } \\
\text { excitement in this park. }\end{array}$ & 3.57 & 1.081 & & & 0.755 & \\
\hline $\begin{array}{l}\text { A6. I would like to meet people with } \\
\text { similar interests and hobbies. }\end{array}$ & 3.87 & 1.088 & & & 0.747 & \\
\hline $\begin{array}{l}\text { Factor 3. Social influence and physical } \\
\text { refreshment (M3) }\end{array}$ & 3.82 & & 0.660 & & & \\
\hline $\begin{array}{l}\text { A10. My friends and family tell me to } \\
\text { visit this park. }\end{array}$ & 3.56 & 1.261 & & & & 0.811 \\
\hline $\begin{array}{l}\text { A11. I would like to refresh my } \\
\text { physical state. }\end{array}$ & 3.97 & 1.066 & & & & 0.649 \\
\hline $\begin{array}{l}\text { A12. I would like to talk about the trip } \\
\text { after I return home. }\end{array}$ & 3.93 & 1.027 & & & & 0.648 \\
\hline Eigenvalues & & & & 3.338 & 2.451 & 1.939 \\
\hline Percentage of variance & & & & 22.251 & 16.341 & 12.924 \\
\hline Cumulative percentage & & & & & 38.592 & 51.516 \\
\hline
\end{tabular}

All items follow the agree-disagree Likert scale.

\subsection{Satisfaction Level of Respondents}

Table 3 indicates that the mean scores of the satisfaction items ranged from 3.44 to 4.35 . Item " $\mathrm{D} 2$. Beautiful scenery and landscape" (4.35) scored the highest among eight satisfaction items, followed by "D1. Diverse species of flora and fauna" (4.14) and "D5. Sufficient security facilities (e.g., parapet and warning signs)" (3.90). This result shows that the natural resources of the parks were key to fulfilling the desire and expectations of the visitors. "D7. Sufficient educational information about biological species" obtained the lowest score among the items, which may imply that the management authorities 
underestimated visitors' expectations related to their needs regarding educational resources and a desire to learn.

Table 3. Exploratory factor analysis (EFA) of tourist satisfaction items.

\begin{tabular}{|c|c|c|c|c|c|}
\hline \multirow[b]{2}{*}{ Factors and Items } & \multirow[b]{2}{*}{ Mean } & \multirow[b]{2}{*}{$\begin{array}{l}\text { Standard } \\
\text { Deviation }\end{array}$} & \multirow[b]{2}{*}{$\begin{array}{l}\text { Cronbach's } \\
\text { Alpha }\end{array}$} & \multicolumn{2}{|c|}{$\begin{array}{c}\text { Rotated (Varimax) } \\
\text { Components Factor Loading }\end{array}$} \\
\hline & & & & 1 & 2 \\
\hline Factor 1. Management and education (S1) & 3.665 & & 0.712 & & \\
\hline D3. Convenience of public transport & 3.63 & 1.087 & & 0.499 & \\
\hline D4. Tourism management of the park & 3.63 & 1.061 & & 0.656 & \\
\hline $\begin{array}{l}\text { D5. Sufficient security facilities } \\
\text { (e.g., parapet, warning signs) }\end{array}$ & 3.90 & 2.717 & & 0.528 & \\
\hline $\begin{array}{l}\text { D6. Sufficient tourism facilities (e.g., tables } \\
\text { and benches, car park, toilets, signposts) }\end{array}$ & 3.70 & 1.046 & & 0.781 & \\
\hline $\begin{array}{l}\text { D7. Sufficient educational information } \\
\text { about biological species }\end{array}$ & 3.44 & 1.089 & & 0.781 & \\
\hline D8. Integrated conservation strategy & 3.69 & 1.030 & & 0.795 & \\
\hline $\begin{array}{l}\text { Factor 2. Natural resources and } \\
\text { environment (S2) }\end{array}$ & 4.245 & & 0.751 & & \\
\hline D1. Diverse species of flora and fauna & 4.14 & 0.866 & & & 0.872 \\
\hline D2. Beautiful scenery and landscape & 4.35 & 0.804 & & & 0.839 \\
\hline Eigenvalues & & & & 2.855 & 2.049 \\
\hline Percentage of variance & & & & 35.691 & 25.617 \\
\hline Cumulative percentage & & & & & 61.308 \\
\hline
\end{tabular}

All items follow the agree-disagree Likert scale.

The underlying dimensions of the satisfaction items were analysed by factor analysis (Table 3). EFA was carried out with varimax rotation. A two-factor solution with eight satisfaction items resulted. The eigenvalues of the two factors were greater than 1.0 and explained $61.31 \%$ of the total variance.

The factor of "management and education (S1)" explained 35.69\% of the variance and obtained an eigenvalue of 2.855 and a Cronbach's alpha of 0.712. Items D3 to D8 were included in this factor. These items reflected the satisfaction of respondents with different aspects of management and policies, such as facilities, safety, conservation in the park and education opportunities. A number of studies on environmental and tourism management and education have identified similar factors $[16,19,44]$. The second factor "natural resources and environment (S2)" explained $25.62 \%$ of the variance and obtained an eigenvalue of 2.049 and a Cronbach's alpha of 0.751 . This factor included items D1 and D2, which captured respondents' satisfaction with nature resources, including animals, plants, scenery and the overall environment. Previous studies on ecotourist satisfaction have also suggested factors regarding natural resources and the environment $[19,43,44]$. This factor had a relatively higher mean score than S1, which means that the expectations of the tourists regarding nature were better fulfilled than those regarding management and education.

\subsection{Association between Sociodemographic $\mathcal{E}$ Visitation Characteristics and Motivation}

The relationships between the sociodemographic characteristics and motivation factors were studied using a multiple regression analysis (Table 4 and Figure 2). Significant positive correlations were found between the factor of "relaxation and nature exploration (M1)" and the visitation rate of national parks $(p<0.05)$ and age $(p<0.05)$; a few studies obtained similar findings that older people usually prefer exploring and appreciating nature $[62,63]$. Significant positive relationships were found between the "novelty seeking (M2)" factor and the visitation rate of national parks $(p<0.01)$. Both the duration of visit $(p<0.01)$ and monthly income $(p<0.05)$ had a significant positive relationship with the "social influence" factor but at different strengths. On the other hand, a significant negative relationship $(p<0.001)$ was found between education level and "social influence". 


\subsection{Association between Sociodemographic E Visitation Characteristics and Satisfaction}

Multiple regression analysis was employed to test the relationships between the sociodemographic factors and satisfaction level (Table 5 and Figure 2). The results showed that the negative relationship between education level and "Management and Education (S1)" was significant $(p<0.01)$, indicating that tourists with higher education levels tended to have lower levels of satisfaction. A significant positive relationship $(p<0.01)$ was found between "Natural Resources and Environment (S2)" and the group size of tourists, indicating that tourists travelling in larger groups were more satisfied with the natural environment.

\subsection{Association between Motivation and Satisfaction}

Multiple regression analysis was employed to study the relationship between motivation factors and the satisfaction level of the tourists (Table 6 and Figure 3). Positive and significant correlations were found between both factors of satisfaction "Management and education (S1)" and "Natural resources and environment (S2)" with all factors of motivations, including "Relaxation and nature exploration (M1)" ( $p<0.001 \& p<0.001$ for S1 \& S2 respectively), "Novelty seeking (M2)" ( $p<0.05 \&$ $p<0.01$ for S1 \& S2 respectively) and "Social influence and physical refreshment (M3)" $(p<0.01 \&$ $p<0.01$ for S1 and S2 respectively).

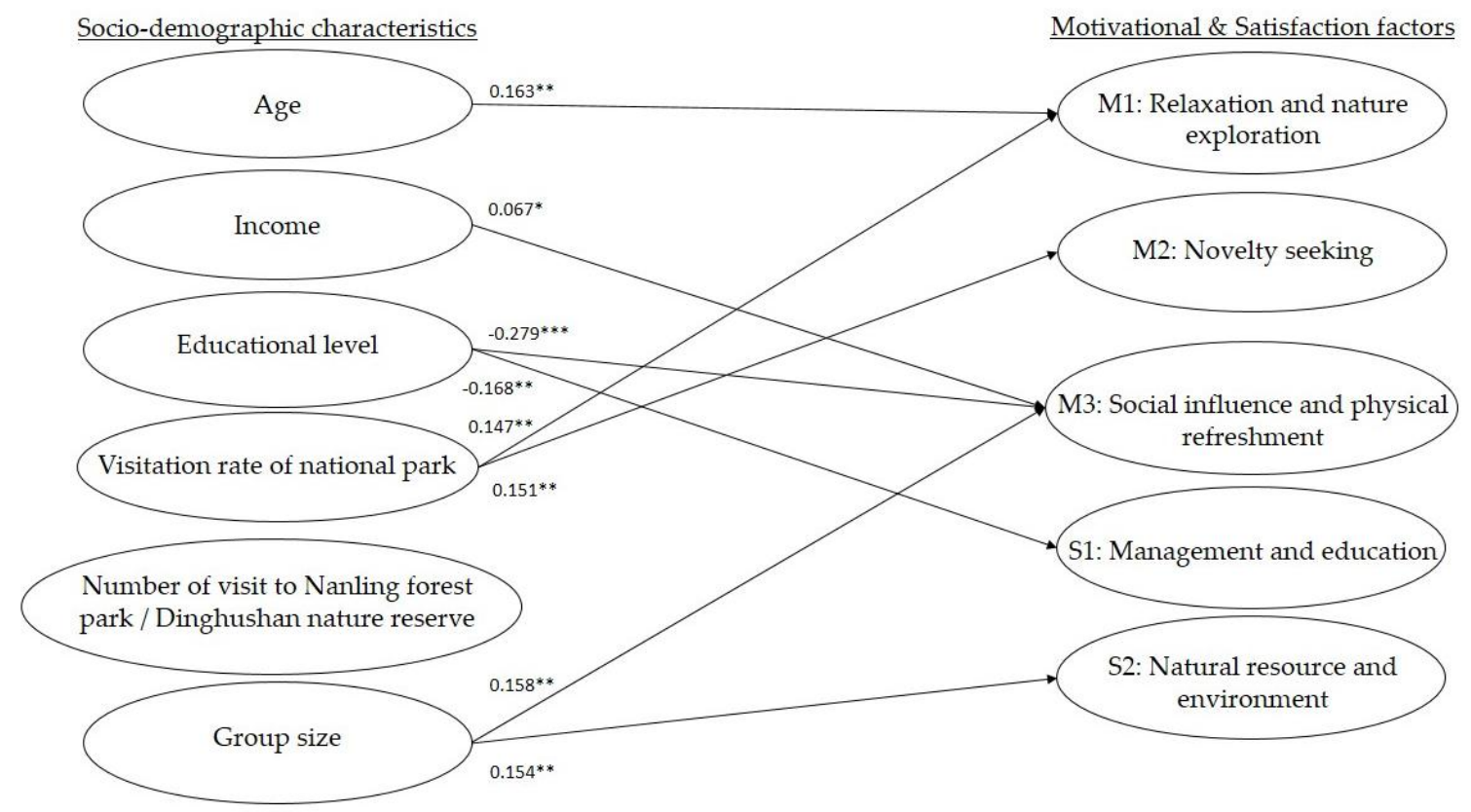

Figure 2. Diagram of multiple-regression model of socio-demographic characteristics, motivation \& satisfaction factors. $* * *$ Significance level at $0.001, * *$ Significance level at $0.005, *$ Significance level at 0.05 . 
Table 4. Linear regression analysis of socio-demographic \& visitation characteristics, motivational factors and satisfaction factors.

\begin{tabular}{|c|c|c|c|c|c|c|c|c|c|}
\hline & \multicolumn{3}{|c|}{ M1. Relaxation and Nature Exploration } & \multicolumn{2}{|c|}{ M2. Novelty Seeking } & \multirow[b]{2}{*}{ Significance } & \multicolumn{3}{|c|}{ M3. Social Influence \& Physical Refreshmen } \\
\hline & $\begin{array}{c}\text { Standardized } \\
\text { Coefficient }\end{array}$ & $\begin{array}{l}\text { Standard } \\
\text { Error }\end{array}$ & Significance & $\begin{array}{c}\text { Standardized } \\
\text { Coefficient }\end{array}$ & $\begin{array}{l}\text { Standard } \\
\text { Error }\end{array}$ & & $\begin{array}{c}\text { Standardized } \\
\text { Coefficient }\end{array}$ & $\begin{array}{l}\text { Standard } \\
\text { Error }\end{array}$ & Significance \\
\hline (Constant) & & 0.359 & 0.070 & & 0.359 & 0.547 & & 0.351 & 0.549 \\
\hline E1. Visitation rate of national parks & 0.147 & 0.069 & 0.007 & 0.151 & 0.069 & 0.006 & -0.034 & 0.068 & 0.613 \\
\hline $\begin{array}{l}\text { E2. Visitation rate of Nanling Forest } \\
\text { Park/Dinghushan nature reserve }\end{array}$ & 0.028 & 0.049 & 0.603 & -0.101 & 0.049 & 0.061 & -0.006 & 0.048 & 0.900 \\
\hline E3. Group size & -0.046 & 0.057 & 0.365 & 0.092 & 0.057 & 0.075 & 0.158 & 0.056 & 0.005 \\
\hline E4. Duration of visit & -0.054 & 0.069 & 0.324 & 0.003 & 0.069 & 0.954 & 0.098 & 0.068 & 0.149 \\
\hline F5. Age & 0.163 & 0.051 & 0.007 & 0.024 & 0.051 & 0.689 & 0.025 & 0.050 & 0.622 \\
\hline F6. Education level & 0.012 & 0.071 & 0.827 & -0.044 & 0.071 & 0.423 & -0.279 & 0.069 & 0.000 \\
\hline F8. Monthly income & 0.05 & 0.032 & 0.381 & -0.088 & 0.032 & 0.121 & 0.067 & 0.032 & 0.035 \\
\hline R2 & 0.049 & & & 0.041 & & & 0.091 & & \\
\hline Adj. R2 & 0.032 & & & 0.024 & & & 0.075 & & \\
\hline F Statistic & 2.849 & & & 2.411 & & & 5.578 & & \\
\hline Standard error & 0.985 & & & 0.987 & & & 0.965 & & \\
\hline
\end{tabular}

Table 5. Multiple regression analysis of sociodemographic \& visitation and satisfaction factors.

\begin{tabular}{|c|c|c|c|c|c|c|}
\hline & \multicolumn{3}{|c|}{ S1. Management and Education } & \multicolumn{3}{|c|}{ S2. Natural Resources and Environment } \\
\hline & $\begin{array}{l}\text { Standardized } \\
\text { Coefficient }\end{array}$ & Standard Error & Significance & $\begin{array}{l}\text { Standardized } \\
\text { Coefficient }\end{array}$ & Standard Error & Significance \\
\hline (Constant) & & 0.359 & 0.004 & & 0.358 & 0.127 \\
\hline E1. Visitation rate of national parks & -0.99 & 0.069 & 0.07 & 0.069 & 0.069 & 0.201 \\
\hline $\begin{array}{l}\text { E2. Visitation rate of Nanling Forest } \\
\text { Park/Dinghushan nature reserve }\end{array}$ & 0.13 & 0.049 & 0.816 & 0.094 & 0.049 & 0.079 \\
\hline E3. Group size & -0.03 & 0.057 & 0.561 & 0.154 & 0.057 & 0.003 \\
\hline E4. Duration of visit & -0.004 & 0.069 & 0.937 & 0.032 & 0.069 & 0.559 \\
\hline F5. Age & 0.021 & 0.051 & 0.731 & 0.033 & 0.051 & 0.576 \\
\hline F6. Education level & -0.168 & 0.071 & 0.002 & -0.08 & 0.071 & 0.14 \\
\hline F8. Monthly income & 0.022 & 0.032 & 0.703 & -0.011 & 0.032 & 0.841 \\
\hline
\end{tabular}


Table 6. Linear regression analysis of motivational factors and satisfaction level.

\begin{tabular}{|c|c|c|c|c|c|c|}
\hline & \multicolumn{3}{|c|}{ S1. Management and Education } & \multicolumn{3}{|c|}{ S2. Natural Resources and Environment } \\
\hline & Standardized Coefficient & Standard Error & Significance & Standardized Coefficient & Standard Error & Significance \\
\hline (Constant) & & 0.048 & 0.996 & & 0.047 & 0.965 \\
\hline M1. Relaxation and nature exploration & 0.197 & 0.048 & 0 & 0.312 & 0.047 & 0 \\
\hline M2. Novelty seeking & 0.101 & 0.048 & 0.038 & 0.127 & 0.047 & 0.007 \\
\hline M3. Social influence and physical refreshment & 0.141 & 0.048 & 0.004 & 0.144 & 0.047 & 0.002 \\
\hline R2 & 0.069 & & & 0.134 & & \\
\hline Adj. R2 & 0.062 & & & 0.128 & & \\
\hline F statistic & 9.765 & & & 20.536 & & \\
\hline Standard error & 0.97 & & & 0.934 & & \\
\hline Dependent variable: Satisfaction & & & & & & \\
\hline
\end{tabular}




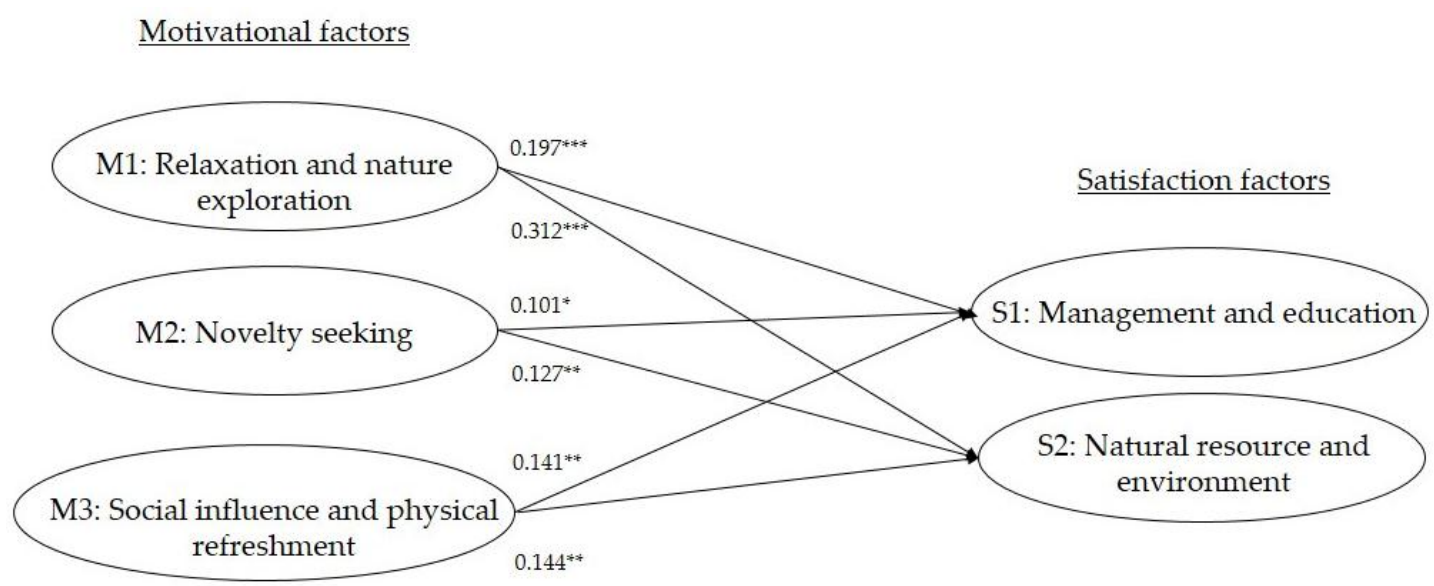

Figure 3. Diagram of multiple-regression model of motivation \& satisfaction factors. ${ }^{* *}$ Significant level at $0.001,{ }^{* *}$ significance level at $0.005,{ }^{*}$ significance level at 0.05 .

\section{Discussion}

Among the three motivational factors, "relaxation and nature exploration (M1)" scored the highest. According to the 2017 Global Most Stressful Cities Ranking, famous Chinese cities such as Shenzhen, Guangzhou, Beijing and Shanghai ranked around the top 50 [64]. Travelling in the natural environment may help Chinese citizens free themselves from the immense pressure of the cities. It is reported that being in contact with nature or travelling in natural environments such as country parks or green spaces could enhance health and help reduce stress $[65,66]$, particularly in the case of urban dwellers [67].

The lowest scored satisfaction item was "Sufficient educational information about biological species (D7)". This item reflected the demand of Chinese tourists for education during ecotourism. Prior studies have suggested that ecotourism development in China focused heavily on infrastructure development and the creation of business opportunities by exploiting the environment, which is similar to mass tourism $[3,68]$. In contrast, relatively little attention was paid to environmental education and environmental awareness promotion, which are key elements of ecotourism. There was likely a mismatch between the highly inadequate attention given to education provision in ecotourism development and the expectations of ecotourists regarding education, which led to low satisfaction for item D7.

Although Chinese tourists are discussed as a group, differences in their satisfaction and motivation were found according to their sociodemographic and visitation characteristics. Education level was shown to be negatively correlated with the satisfaction factor of "management and education (S1)". This result contradicts a previous study on Western ecotourists suggesting that more-educated people tend to be more satisfied with ecotours [19]. This result may yield several explanations. The abovementioned mismatch between the expectations of tourists and nature-based tourism development in China is one major reason. A higher level of education was associated with a higher level of environmental awareness and a positive environmental attitude [69,70]. The high awareness and knowledge of this group of people would allow them to notice and understand the shortcomings and unsustainability of ecotourism practices and management in China. Cheung and Jim [71] indicated that people with higher education tended to have higher expectations regarding the quality of nature-based tourism services. This result suggests that the management of protected areas has failed to keep up with the increase in educational level and expectation of visitors. Apart from paying attention to hardware development (e.g., infrastructure), authorities of protected areas may shift some of their attention to the development of software, particularly in conservation practices and education. A higher level of conservation practice could help maintain the condition of the protected area, and thus the satisfaction of tourists. On the other hand, more education opportunities could help fulfill the desire of visitor to 
learn as well as raise the awareness of visitors on protecting the environment, which could ultimately help to conserve the protected area.

Similar to the case of satisfaction, sociodemographic and visitation characteristics are also good predictors of motivation and have contributed to a number of significant findings in this study. The motivational factors "relaxation and nature exploration (M1)" and "novelty seeking (M2)" were positively correlated with the visitation rate of forest national parks. This result was consistent with the finding of Lee et al. [38] that motivations related to knowledge seeking, appreciation, interaction with nature and relaxation were positive predictors of the repeated visits of tourists to nature-based destinations. Another study suggested that the higher experiential value of nature-based tourism could promote repeated visits to nature destinations in the future [72]. The respondents in this study were highly satisfied with "Natural resources and environment (S2)", and the tourists motivated by M1 and M2 were positively correlated with S2. The satisfaction of tourists motivated by M1 and M2 would enhance their experiential value and thus the visitation rate of national parks or nature reserves in the future.

Regarding the positive correlation between group size and the motivation of "social influence and physical refreshment", Bieger and Laesser [39] previously showed that more socially motivated family travelers usually travel in larger group sizes than travelers who are not as influenced by social factors. It is reasonable that socially influenced visitors travel with their family members or friends who may have encouraged or requested them to travel, resulting in a relatively larger group size.

Numerous studies consider that age, educational level and income can reflect motivation $[12,36,37,39,73]$; yet, these characteristics have rarely been discussed with reference to Chinese cultures. In fact, Chinese culture is highly associated with these three characteristics, which may help to explain the influence of sociodemographic characteristics on tourist motivation.

This study finds that education level and motivation related to social influence are negatively correlated. This result is consistent with the result of Chen, Bao and Huang [36], which suggested that social-seeking Chinese backpackers tend to be less educated. This phenomenon can be explained by the characteristic Chinese culture of collectivism. Collectivism is an important part of the Chinese culture that helps individuals maintain social relationships among family and friends. Another study showed that Chinese tourists scored low on "individualism" [74], further confirming the importance of collectivism. The tendency towards collectivism causes Chinese individuals to be easily influenced by family and friends in terms of their travel decisions [12] and to respect travel invitations or suggestions [75]. In contrast, it has been suggested that more Westernized and educated Chinese tends to be more individualistic [75]. This suggestion is consistent with the finding of Kim and Lee [76] that Anglo-American tourists were not as affected by travel motivations of "family togetherness" or "prestige and status" and showed a much higher level of individualism than Japanese tourists, who are similar to the Chinese regarding the tradition of collectivism. The study by Bieger and Laesser [39] on Swiss tourists showed that Western tourists with middle to high education levels tend to travel either individually or in small groups. These results may prove that higher levels of education, particularly Western education, would reduce the influence of the traditional Chinese culture on collectivism but promote individualism, making people less prone to societal influences. To address the collectivism of Chinese tourists, protected areas may provide more differentiated activity options to different kinds of tourists. Western tourists typically prefer individual tours and self-guided trekking [39]. For instance, private group tours may be promoted to accommodate the preference of Chinese tourists to stay together and allow better control on the behavior of the tourist as well as education.

Chinese culture has obviously shaped Chinese tourists to act and think in a very different way from Western tourists. Jensen [37], in studying Danish travelers, found that income level was not related to "social relationship" and "prestige and impression". Bieger and Laesser [39] showed that Swiss tourists with the highest income levels tended to be motivated by nature or cultural elements instead of social or family reasons, which were more common for the lower income groups. Conversely, this study identified a positive correlation between monthly income and the social motivation of Chinese tourists. 
The well-known Chinese values regarding "face" and "guanxi" may explain the unique characteristics of Chinese tourists. These two values have been reported to be highly significant in shaping the behaviour and motivation of Chinese tourists [73]. "Face" is important for Chinese individuals, as it denotes one's social status and position, helping them feel prestige and self-esteem and maintaining the feelings of power and privilege $[62,63,73]$. Wealth and the ability to consume have always been recognized as excellent representations of "face" [62]. Pearce, et al. [77] reported that Chinese tourists tend to visit famous destinations, purchase items and share their experiences to prove to their family and friends that they are capable of travelling and gaining prestige and "face". This desire to gain "face" is mostly associated with family and friends [63], which explains the motivational factor of social influence, indicating that tourists are either encouraged by their family or friends or are trying to prove their ability to them. The desire to gain "face" by showing off one's wealth by travelling could be further explained by the concept of "guanxi". "Guanxi" is the establishment of social relationships and a network with people of similar social status, background and power [62,78]. People with higher incomes would like to maintain "guanxi" with their relevant social group by showing that they have "face" as evidenced by their consumption and travelling, which can help maintain their social position, power and privilege. Therefore, people with higher incomes tend to be more motivated by social influence, as they have a greater need to prove their "face" and maintain "guanxi" with their family and friends in high social positions.

Following the translation of sociodemographic characteristics into motivation, the links between motivation and satisfaction represent the next relationship that is of concern. All the motivational factors were shown to be positively correlated with both satisfaction factors of "Management and education (S1)" and "Natural resources and environment (S2)". A previous study conducted in New Zealand forest parks suggested that a higher level of motivation in nature-based tourists could be associated with higher satisfaction [79]. It is suggested that a stronger motivation could lead to a higher level of commitment and thus a higher level of success and a feeling of satisfaction [80], which explains why all the correlations found in this study were positively correlated.

Chinese tourist in this study were shown to be characterized by a few traits; they were primarily motivated by nature exploration. At the same time, their relatively low satisfaction on management and education, particularly education of environmental and biological information, may imply that tourism in protected areas of China is at most nature-based tourism but not ecotourism. One of the main criteria of ecotourism is to provide education opportunity and raise environmental awareness [81], which is crucial for promoting environmentally responsible behavior of tourists and to prevent excessive impacts like mass tourism would bring. Given the huge scale of tourism in protected areas in China, nature-based tourism would likely be part of the larger mass tourism market. Apart from improving the education work in protected areas, hardening work and enhancement work on cultural features, overexploitation and severe impacts on the environment which would commonly be caused by mass tourism can be avoided. As discussed in some studies [81,82], mass tourism and ecotourism may not always be contradictory, instead, mass tourism or soft ecotourism could be the way to develop a sustainable ecotourism destination. Well-developed and well-known protected areas around the world are never short of mass tourists, yet, proper management could turn threats into opportunities, as evidenced by the Yellowstone in USA or Great Barrier Reef in Australia [81]. Understanding the characteristics and behavior of Chinese tourists would be the key to allow management authorities to manipulate tourists in a sustainable way and funnel great amount of mass tourism earnings into conserving and managing protected areas in China as well as around the world.

The major argument of this study suggests that due to the difference in tourist characteristics, traditional management approaches and studies should not be directly applied on the management of Chinese tourists and protected areas. On this basis, the following suggestions based on Chinese tourist characteristics are made. Regarding the management of protected area, China does not categorize their protected area according to the IUCN categories [83]. Given the significant cultural value of natural landscape, category V protected area of the IUCN standard would be a suitable category for 
the two studied protected areas, and other protected areas that are also more culturally significant than environmental to follow as a reference for management. Category $\mathrm{V}$ protected landscape is characterized by the association of human-nature interaction in the area and serves to conserve the landscape in all aspect including environmental and cultural [84]. In fact, as suggested above and by Sofield and $\mathrm{Li}$ [22], the Chinese view nature in an anthropocentric way, in contrast to the biocentric approach of the Western standard. The Chinese appreciate nature as a cultural ground with human alternations, while the ideal nature environment of the Western world would be in the wilderness form. Therefore, the Western approach may not always apply to managing and organizing a protected area in China. Management efforts in Chinese protected areas should focus more on conserving the cultural features of the environment, like the traditional buildings and geological features of the area. Instead of minimizing alterations in the Western standards, a lot of enhancement work should be done on the existing cultural attractions within the protected areas. For instance, Sofield and Li [22] in their work stated that in Huang Shan, concrete stairs cutting through a slope, pavilions are provided and calligraphy on cliff are painted artificially. These alterations would not be ideal by the Western standard, yet it provides an authentic experience of nature for the Chinese, as these works resemble the historical setting of the environment and allowed the interaction of human and nature in the Chinese way. Category V allows a higher degree of alteration to the environment as well as having a higher capability of catering to mass tourists or soft ecotourists [81], and would therefore be suitable as a reference.

In this study, two protected areas in South China were chosen as the study area and the data collected were analyzed as one sample. This could be a potential limitation as the socio-demographics, motivation and satisfaction characteristics of visitors of two sites could possibly be different in the first place. Given the huge and diversified population in China, tourist's visiting different protected areas could hardly be identical. Further studies may consider conducting surveys in more protected areas, confirm the similarities of sites by statistical tests and only using similar sites for the research. The results and discussion of this study supported the suggestion that management strategies should be adaptive with regards to the characteristics, background and culture of tourists. Therefore, future studies may explore more types of tourists, e.g., backpacking, or tourists with other nationalities and distinctive cultural backgrounds, to add more nuances to mainstream studies based on Western nature-based tourists.

\section{Conclusions}

This study discussed different types of tourist information and presented a bigger and clearer picture of the complicated linkages between the sociodemographic and visitation characteristics, motivation and satisfaction of Chinese tourists. EFA was carried out, three motivational and two satisfaction factors were identified. Many of the correlations discovered are highly related to traditional Chinese culture and values, showing that Chinese tourists' unique characteristics are influenced by culture, which marked the difference between Chinese and Western tourists. Chinese tourists were primarily motivated by nature exploration and showed a relatively low level of satisfaction with education and management. These results further confirm the importance of this study as it reveals differences between Chinese tourists and the widely-studied Western tourists. It helps highlight this study's key argument that traditional Western approaches on protected areas and tourist management may not directly apply when it comes to Chinese tourists and protected areas, implying that management strategies should be adaptive and specific according to the distinctive culture and background of Chinese tourists. Based on the difference in tourist characteristics, this study provides crucial suggestions for the management of Chinese tourists and protected areas both domestically and internationally. This study has explored only the nature-based tourists in South China's protected areas, which may not totally represent tourists across the whole of China. Future studies may carry out more surveys in more diverse locations across China. 
Author Contributions: A.T.H.M. and L.T.O.C. design the research, analyze the data and draft the manuscript; A.S.Y.C. and K.M.Y.L. drafted the manuscript; S.L. carried out the field work and analyzed the data.

Funding: Dean's Research Grant, FLASS, EdUHK (ECR6 2015).

Acknowledgments: The authors are grateful to the Dean's Research Grant, FLASS for providing funding support for this research project (Grant number: ECR6 2015).

Conflicts of Interest: The authors declare no conflict of interest.

\section{References}

1. China Tourism Academy. Big Data of Chinese Outbound Tourist 2016; China Tourism Academy: Beijing, China, 2017.

2. World Travel \& Tourism Council. Travel \& Tourism Economic Impact 2017, China; World Travel \& Tourism Council: London, UK, 2017.

3. Arlt, W. China's Outbound Tourism; Routledge: Abingdon-on-Thames, UK, 2006.

4. Farrell, K.; Westlund, H. China's rapid urban ascent: An examination into the components of urban growth. Asian Geogr. 2018, 35, 85-106. [CrossRef]

5. O'Connor, K.; Fuellhart, K.; Zhang, S. Change in the role of cities in China's air transport 2005-2015. Asian Geogr. 2018. [CrossRef]

6. The World Bank. Urban Population (\% of Total). Available online: https://data.worldbank.org/topic/ urban-development?locations=CN\&view $=$ chart (accessed on 23 January 2018).

7. Matus, K.; Nam, K.M.; Selin, N.E.; Lamsal, L.N.; Reilly, J.M.; Paltsev, S. Health damages from air pollution in China. Glob. Environ. Chang. 2012, 22, 55-66. [CrossRef]

8. Wang, Y. Environmental degradation and environmental threats in China. Environ. Monit. Assess. 2004, 90, 161-169. [CrossRef] [PubMed]

9. Chan, R.Y. Determinants of Chinese consumers' green purchase behavior. Psychol. Mark. 2001, 18, $389-413$. [CrossRef]

10. Li, W.; Han, N. Ecotourism management in China's nature reserves. Ambio 2001, 30, 62-63. [CrossRef]

11. State Forestry Administration of the People's Republic of China. Development and Management of Forest Park in China 2015; State Forestry Administration of the People's Republic of China: Beijing, China, 2015.

12. Sparks, B.; Pan, G.W. Chinese outbound tourists: Understanding their attitudes, constraints and use of information sources. Tour. Manag. 2009, 30, 483-494. [CrossRef]

13. Eagles, P.F.; McCool, S.F.; Haynes, C.D.; Phillips, A. Sustainable Tourism in Protected Areas: Guidelines for Planning and Management; IUCN: Gland, Switzerland, 2002; Volume 8.

14. Lee, T.H. A structural model to examine how destination image, attitude, and motivation affect the future behavior of tourists. Leis. Sci. 2009, 31, 215-236. [CrossRef]

15. Lee, A.K.; Abrahams, R.A. Naturalizing people, ethnicizing landscape: Promoting tourism in China's rural periphery. Asian Geogr. 2018. [CrossRef]

16. Adam, I.; Adongo, C.A.; Amuquandoh, F.E. A structural decompositional analysis of eco-visitors' motivations, satisfaction and post-purchase behaviour. J. Ecotour. 2017, 1-22. [CrossRef]

17. Kim, S.S.; Kim, M.; Park, J.; Guo, Y. Cave tourism: Tourists' characteristics, motivations to visit, and the segmentation of their behavior. Asia Pac. J. Tour. Res. 2008, 13, 299-318. [CrossRef]

18. Ozdemir, B.; Aksu, A.; Ehtiyar, R.; Çizel, B.; Çizel, R.B.; İçigen, E.T. Relationships among tourist profile, satisfaction and destination loyalty: Examining empirical evidences in Antalya region of Turkey. J. Hosp. Mark. Manag. 2012, 21, 506-540. [CrossRef]

19. Tsiotsou, R.; Vasioti, E. Using demographics and leisure activities to predict satisfaction with tourism services in Greece. J. Hosp. Leis. Mark. 2006, 14, 69-82. [CrossRef]

20. Jönsson, C.; Devonish, D. Does nationality, gender, and age affect travel motivation? A case of visitors to the Caribbean island of Barbados. J. Travel Tour. Mark. 2008, 25, 398-408. [CrossRef]

21. Packer, J.; Ballantyne, R.; Hughes, K. Chinese and Australian tourists' attitudes to nature, animals and environmental issues: Implications for the design of nature-based tourism experiences. Tour. Manag. 2014, 44, 101-107. [CrossRef]

22. Sofield, T.; Li, F.M.S. China: Ecotourism and cultural tourism, harmony or dissonance. Crit. Issues Ecotour. Underst. Complex Tour. Phenom. 2007, 368-385. 
23. Cheung, L.T. The effect of geopark visitors' travel motivations on their willingness to pay for accredited geo-guided tours. Geoheritage 2016, 8, 201-209. [CrossRef]

24. Cheung, L.T.; Fok, L. The motivations and environmental attitudes of nature-based visitors to protected areas in Hong Kong. Int. J. Sustain. Dev. World Ecol. 2014, 21, 28-38. [CrossRef]

25. Cheung, L.T.; Lo, A.Y.; Fok, L. Recreational specialization and ecologically responsible behaviour of Chinese birdwatchers in Hong Kong. J. Sustain. Tour. 2017, 25, 817-831. [CrossRef]

26. Chow, A.S.; Cheng, I.N.; Cheung, L.T. Self-determined travel motivations and ecologically responsible attitudes of nature-based visitors to the Ramsar wetland in South China. Ann. Leis. Res. 2017. [CrossRef]

27. Fung, C.K.; Jim, C. Segmentation by motivation of Hong Kong Global Geopark visitors in relation to sustainable nature-based tourism. Int. J. Sustain. Dev. World Ecol. 2015, 22, 76-88.

28. Liu, K.S.; Gou, G.R.; Cheung, L.T. Understanding participants' motivation and willingness to pay for joining ecotourism training courses in Hong Kong. Asian Geogr. 2016, 33, 23-34. [CrossRef]

29. Mehmetoglu, M.; Normann, $\varnothing$. The link between travel motives and activities in nature-based tourism. Tour. Rev. 2013, 68, 3-13. [CrossRef]

30. Beh, A.; Bruyere, B.L. Segmentation by visitor motivation in three Kenyan national reserves. Tour. Manag. 2007, 28, 1464-1471. [CrossRef]

31. Crompton, J.L. An assessment of the image of Mexico as a vacation destination and the influence of geographical location upon that image. J. Travel Res. 1979, 17, 18-23. [CrossRef]

32. Saayman, M.; Saayman, A. Why travel motivation and socio-demographics matter in managing a national park. Koedoe 2009, 51. [CrossRef]

33. Holden, A.; Sparrowhawk, J. Understanding the motivations of ecotourists: The case of trekkers in Annapurna, Nepal. Int. J. Tour. Res. 2002, 4, 435-446. [CrossRef]

34. Luo, Y.; Deng, J. The New Environmental Paradigm and nature-based tourism motivation. J. Travel Res. 2008, 46, 392-402. [CrossRef]

35. Jang, S.S.; Feng, R. Temporal destination revisit intention: The effects of novelty seeking and satisfaction. Tour. Manag. 2007, 28, 580-590. [CrossRef]

36. Chen, G.; Bao, J.; Huang, S.S. Segmenting Chinese backpackers by travel motivations. Int. J. Tour. Res. 2014, 16, 355-367. [CrossRef]

37. Jensen, J.M. The relationships between socio-demographic variables, travel motivations and subsequent choice of vacation. In Proceedings of the 2nd International Conference on Economics, Business and Management, Singapore, 26-28 Feburary 2012; pp. 37-44.

38. Lee, S.; Lee, S.; Lee, G. Ecotourists' motivation and revisit intention: A case study of restored ecological parks in South Korea. Asia Pac. J. Tour. Res. 2014, 19, 1327-1344. [CrossRef]

39. Bieger, T.; Laesser, C. Market segmentation by motivation: The case of Switzerland. J. Travel Res. 2002, 41, 68-76. [CrossRef]

40. Beard, J.G.; Ragheb, M.G. Measuring leisure satisfaction. J. Leis. Res. 1980, 12, 20. [CrossRef]

41. Buckley, R. Ecotourism: Principles and Practices; CABI: Wallingford, UK, 2009.

42. Oliver, R.L. A cognitive model of the antecedents and consequences of satisfaction decisions. J. Mark. Res. 1980, 460-469. [CrossRef]

43. Meng, F.; Tepanon, Y.; Uysal, M. Measuring tourist satisfaction by attribute and motivation: The case of a nature-based resort. J. Vacat. Mark. 2008, 14, 41-56. [CrossRef]

44. Lee, C.F. Tourist satisfaction with forest recreation experience: A segment-based approach. Anatolia 2015, 26, 535-548. [CrossRef]

45. Huang, Y.; Luo, S.; Ding, P.; Scott, N. Impressions of Liusanjie: A study of motivation, theatrical performance evaluation, and satisfaction. Curr. Issues Tour. 2014, 17, 280-296. [CrossRef]

46. Liang, J.H.; Liang, R.D.; Wang, H.Y. The impact of tourist image and travel motivation on satisfaction in PengHu Geological Park. Sport Recreat. Res. 2010, 4, 116-138.

47. Lee, T.H. An ecotourism behavioural model of national forest recreation areas in Taiwan. Int. For. Rev. 2007, 9, 771-785. [CrossRef]

48. Barros, C.P.; Machado, L.P. The length of stay in tourism. Ann. Tour. Res. 2010, 37, 692-706. [CrossRef]

49. State Forestry Administration of the People's Republic of China. Development and Management of Forest Park in China 2016; State Forestry Administration of the People's Republic of China: Beijing, China, 2017. 
50. Dinghushan Nature Reserve Management Authority. Social Environment. Available online: http:/ / www. dhs.scib.cas.cn/gkjj/qqgk_shhj/ (accessed on 11 January 2018).

51. Eagles, P.F. The travel motivations of Canadian ecotourists. J. Travel Res. 1992, 31, 3-7. [CrossRef]

52. Podsakoff, P.M.; MacKenzie, S.B.; Podsakoff, N.P. Sources of method bias in social science research and recommendations on how to control it. Annu. Rev. Psychol. 2012, 63, 539-569. [CrossRef] [PubMed]

53. Cronbach, L.J. Coefficient alpha and the internal structure of tests. Psychometrika 1951, 16, 297-334. [CrossRef]

54. Tavakol, M.; Dennick, R. Making sense of Cronbach's alpha. Int. J. Med. Educ. 2011, 2, 53. [CrossRef] [PubMed]

55. Bland, J.M.; Altman, D.G. Statistics notes: Cronbach's alpha. BMJ 1997, 314, 572. [CrossRef] [PubMed]

56. Nunnally, J.C.; Bernstein, I.H. Psychometric Theory; McGraw-hill: New York, NJ, USA, 1967; Volume 226.

57. Nunnally, J.C.; Bernstein, I.H. Psychometric Theory; McGraw-Hill Series in Psychology; McGraw-Hill: New York, NY, USA, 1994; Volume 3.

58. Kaiser, H.F. The application of electronic computers to factor analysis. Educ. Psychol. Meas. 1960, 20, 141-151. [CrossRef]

59. Ferguson, E.; Cox, T. Exploratory factor analysis: A users' guide. Int. J. Select. Assess. 1993, 1, 84-94. [CrossRef]

60. Podsakoff, P.M.; MacKenzie, S.B.; Lee, J.Y.; Podsakoff, N.P. Common method biases in behavioral research: A critical review of the literature and recommended remedies. J. Appl. Psychol. 2003, 88, 879. [CrossRef] [PubMed]

61. Hair, J.F.; Black, W.C.; Babin, B.J.; Anderson, R.E.; Tatham, R.L. Análise Multivariada de Dados; Bookman Editora: Porto Alegre, Brazil, 2009.

62. Hwang, K.K. Face and favor: The Chinese power game. Am. J. Sociol. 1987, 92, 944-974. [CrossRef]

63. Li, J.J.; Su, C. How face influences consumption. Int. J. Mark. Res. 2007, 49, 237-256.

64. Zipjet. The 2017 Global Least \& Most Stressful Cities Ranking. Available online: https:/ /www.zipjet.co.uk/ 2017-stressful-cities-ranking (accessed on 21 February 2018).

65. Jim, C.; Shan, X. Socioeconomic effect on perception of urban green spaces in Guangzhou, China. Cities 2013, 31, 123-131. [CrossRef]

66. Maller, C.; Townsend, M.; St Leger, L.; Henderson-Wilson, C.; Pryor, A.; Prosser, L.; Moore, M. Healthy parks, healthy people: The health benefits of contact with nature in a park context. George Wright Forum 2009, 26, 51-83.

67. Ng, S.; Zhang, Y.; Ng, K.; Wong, H.; Lee, J. Living environment and quality of life in Hong Kong. Asian Geogr. 2018, 35, 35-51. [CrossRef]

68. Yi, L. Ecotourism in Western Sichuan, China. Mt. Res. Dev. 2002, 22, 113-115.

69. Aminrad, Z.; Zakaria, S.; Hadi, A.S. Influence of age and level of education on environmental awareness and attitude: Case study on Iranian students in Malaysian Universities. Soc. Sci. 2011, 6, 15-19. [CrossRef]

70. Shen, J.; Saijo, T. Reexamining the relations between socio-demographic characteristics and individual environmental concern: Evidence from Shanghai data. J. Environ. Psychol. 2008, 28, 42-50. [CrossRef]

71. Cheung, L.T.; Jim, C. Ecotourism service preference and management in Hong Kong. Int. J. Sustain. Dev. World Ecol. 2013, 20, 182-194. [CrossRef]

72. Chien, M. An empirical study on the effect of attractiveness of ecotourism destination on experiential value and revisit intention. Appl. Ecol. Environ. Res. 2016, 15, 43-53. [CrossRef]

73. Li, M.; Cai, L.A. The effects of personal values on travel motivation and behavioral intention. J. Travel Res. 2012, 51, 473-487. [CrossRef]

74. Agrusa, J.; Kim, S.S.; Wang, K.C. Mainland Chinese tourists to Hawaii: Their characteristics and preferences. J. Travel Tour. Mark. 2011, 28, 261-278. [CrossRef]

75. Deng, J.; Walker, G.J.; Swinnerton, G. A comparison of environmental values and attitudes between Chinese in Canada and Anglo-Canadians. Environ. Behav. 2006, 38, 22-47. [CrossRef]

76. Kim, C.; Lee, S. Understanding the cultural differences in tourist motivation between Anglo-American and Japanese tourists. J. Travel Tour. Mark. 2000, 9, 153-170. [CrossRef]

77. Pearce, P.L.; Wu, M.Y.; Osmond, A. Puzzles in understanding Chinese tourist behaviour: Towards a triple-C gaze. Tour. Recreat. Res. 2013, 38, 145-157. [CrossRef]

78. Yau, O.H.; Chan, T.S.; Lau, K.F. Influence of Chinese cultural values on consumer behavior: A proposed model of gift-purchasing behavior in Hong Kong. J. Int. Consum. Mark. 1999, 11, 97-116. [CrossRef] 
79. Pan, S.; Ryan, C. Mountain areas and visitor usage-motivations and determinants of satisfaction: The case of Pirongia Forest Park, New Zealand. J. Sustain. Tour. 2007, 15, 288-308. [CrossRef]

80. Ryan, C. Researching Tourist Satisfaction: Issues, Concepts, Problems; Routledge: Abingdon-on-Thames, UK, 1995.

81. Weaver, D.B. The Encyclopedia of Ecotourism; CABI: Wallingford, UK, 2001.

82. Weaver, D.B. Ecotourism as mass tourism: Contradiction or reality? Cornell Hotel Restaur. Adm. Q. 2001, 42, 104-112. [CrossRef]

83. IUCN. Category V: Protected Landscape/Seascape. Available online: https://www.iucn.org/theme/ protected-areas/about/protected-areas-categories/category-v-protected-landscapeseascape (accessed on 15 January 2018).

84. Kan, J.M.; Zhi, W.; Qing, Z.G.; Ming, T.S.; Li, Z.H. Categorization standard of nature protected area in China based on the standard of IUCN. J. Ecol. Rural Environ. 2004, 20, 1-6.

(C) 2018 by the authors. Licensee MDPI, Basel, Switzerland. This article is an open access article distributed under the terms and conditions of the Creative Commons Attribution (CC BY) license (http://creativecommons.org/licenses/by/4.0/). 